Article

\title{
Variables Affecting Peri-Implant Radiographic Bone Loss-8-23 Years Follow-Up
}

\author{
Michael Saminsky ${ }^{1, * \mathbb{D}}$, Anat Ben Dor ${ }^{2}$ and Jacob Horwitz ${ }^{2,3} \mathbb{D}$ \\ 1 Department of Periodontology and Implant Dentistry, Goldschleger School of Dental Medicine, \\ Tel-Aviv University, Ramat Aviv 39040, Israel \\ 2 Department of Periodontology, Rambam Health Care Campus, Haifa 3109601, Israel; \\ anat.bendor.huji@gmail.com (A.B.D.); j_horwitz@rambam.health.gov.il (J.H.) \\ 3 Private Periodontal Practice, Tel-Aviv 6905154, Israel \\ * Correspondence: sachermiki@gmail.com
}

Received: 18 October 2020; Accepted: 28 November 2020; Published: 30 November 2020

\begin{abstract}
The aim of this study is to evaluate factors associated with long-term peri-implant bone-loss and to create a statistical model explaining bone-loss. The dental records in a private periodontal practice were screened for implant-patients with a minimal follow-up period of 8 years with periapical radiographs at implant-placement (T0) and last follow-up (Tf). Collected data included demographics, general health, medications, periodontal parameters, implant parameters, bone augmentation procedures, restoration and antagonist data, number of supportive periodontal appointments (SPT), and radiographic bone-loss between T0 and Tf . Bivariate and Mixed Logistic Regression analyses were performed. "Goodness-of-fit" of the model was elaborated with Receiver Operating Characteristic Curve (ROC) analyses. Thirty-seven patients receiving 142 implants were included. Mean clinical follow-up period was $11.7 \pm 3.7$ years (range 8-23). Most implants $64.4 \%$ were SPT-maintained more than twice a year. Patients with osteoporosis and smokers were prone to increased radiographic peri-implant bone-loss. External-hex implants placed without guided bone regeneration (GBR) and implants 10-12 $\mathrm{mm}$ long and diameter of 3.7-4 $\mathrm{mm}$ showed less peri-implant bone-loss. The model's Area Under the Curve (AUC) was 76.9\% (Standard Error 4.6\%, CI 67.8-86\%).
\end{abstract}

Keywords: long-term follow-up; dental implant; marginal bone loss; periodontal private practice

\section{Introduction}

Installation of dental implants for fixed or removable rehabilitation has become a common practice in the last decades [1,2], and its high rates of survival and success are well documented [3,4]. It is currently accepted that implants go through periods of physiological remodeling after implant placement and after completion of implant-supported prosthesis, after which comes a period of steady state [5]. Periapical radiographs are the standard imaging tool to monitor peri-implant bone level, which manifests itself as physiological remodeling of crestal bone loss varying between 0.5 and $2 \mathrm{~mm}$ from implant installation to initial loading [6,7] followed by a steady state when the average annual decrease in peri-implant bone level is less than $0.1 \mathrm{~mm} /$ year [8]. The average measurement error of radiographic bone loss is defined as $0.5 \mathrm{~mm}$ [9]. Therefore, if no significant bone loss occurs during the steady state period, implants should be followed for at least 5 years before significant bone loss exceeds measurement error. The current classification of an implant with peri-implantitis in the absence of a radiograph after initial healing/loading comprises bone loss $\geq 3 \mathrm{~mm}$ apical of the most coronal portion of the intra-osseous part of the implant together with probing pocket depth of $\geq 6 \mathrm{~mm}$ and bleeding on probing [9]. This definition takes into account the initial physiological remodeling as well as bone loss during the ensuing period. 
Cases from "everyday practices" may enhance our understanding regarding the effectiveness of implant therapy. The evidence in implant therapy comes from private practices [10-13] and from patients treated in university clinics $[3,10,14]$, yet more private practice data would be valuable.

We looked for patients in a single private practice who received dental implants and had documentation at least 8 years following implant installation. The main objective of the present study was to evaluate factors that were associated with long term peri-implant bone loss. Additional aim was to create a statistical model that may explain radiographic bone changes around dental implants.

\section{Materials and Methods}

The present retrospective observational study is based on data collected from clinical patients' files in one private practice. The study was approved by the Rambam Health Care Campus review board (0298-19-RMB). The dental records of patients attending a private periodontal practice who received dental implants as a part of their periodontal treatment or as a stand-alone procedure were screened. Periodontal and implant therapy throughout the entire study period were performed by the same periodontist $(\mathrm{JH})$. The restorative therapy was provided by referring clinicians. The clinic's patient database was screened for patients who had clinical periodontal data from the time of implant installation (T0) and from at least 8 years later ( $\mathrm{T} f$ ). This cohort was further screened for patients who had orthoradial radiographs from $\mathrm{T} 0$ and from $\mathrm{T} f$ for measuring the distance between implant shoulder and the most coronal bone level (Figure 1). The final database consisted of patients who had both clinical and radiographic data of appropriate diagnostic quality. No other inclusion/exclusion criteria were used for patient selection. Generally, patients received periodontal active therapy that consisted of cause-related therapy, including oral hygiene instructions and motivation, scaling and root surface debridement, and surgical therapy as necessary. Patients that were additionally diagnosed with caries, defective restorations, and/or endodontal conditions were referred back to their referring dentist for dental treatment. After completion of this phase, implants were planned and installed. Some cases also required bone augmentation procedures. Patients also entered the supportive periodontal therapy (SPT) phase (the standard recommendation consisting of oral screening, oral hygiene motivation, scaling, and root and implant surface decontamination using ultrasonic and hand instruments every 3 months).

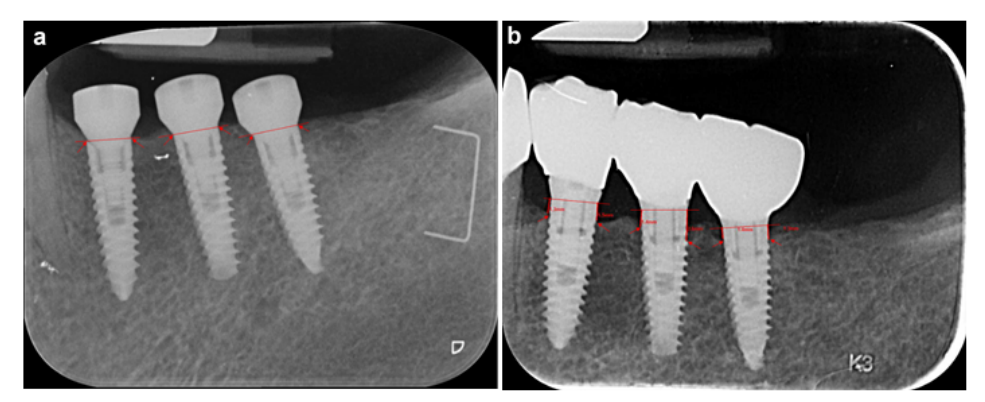

Figure 1. A periapical radiograph at the implant site, at implant placement date $\mathrm{T} 0$ and at the last follow-up visit $\mathrm{T} f$. (a) Intraoral periapical radiograph of three implants replacing left mandibular premolar and first and second molars at T0. The drown lines and arrows do not show any mesial and distal distance between implant shoulder and the bone crest (no bone resorption is observed). (b) Intraoral periapical radiograph of the same implants at $\mathrm{T} f, 8$ years later. The drown lines depict mesial and distal distance between implant shoulder and the bone crest $(1.3 \mathrm{~mm} ; 1.5 \mathrm{~mm}, 1.4 \mathrm{~mm}$; $2.6 \mathrm{~mm}, 1.0 \mathrm{~mm} ; 1.3 \mathrm{~mm}$, respectively mesial and distal from the second premolar to the second molar). 
For the present study, the following data were collected from patients' files.

\subsection{General Data}

Gender, age, general health status (presence of diabetes mellitus, cardiovascular disease, osteoporosis) medications associated with gingival side effects: calcium channel blockers (CaCB), phenytoin, cyclosporine [15-17], and smoking status (smoker/non-smoker).

\subsection{Dental Data}

Number of teeth and implants present in mouth, number of sites with periodontal pockets $5 \mathrm{~mm}$ or deeper, and full mouth bleeding score and plaque index (FMBS and PII, respectively) $[18,19]$ at T0 and $\mathrm{T} f$. Number of SPT appointments performed between $\mathrm{T} 0$ and $\mathrm{T} f$.

\subsection{Implant Data}

I. Brand, length, and diameter; connection type (internal hex or external hex) of implants that were installed at T0; installation timing (immediate, early (up to 8 weeks after tooth extraction), late (healed ridge)); bone augmentation data: guided bone regeneration (GBR)-yes/no, sinus floor augmentation-yes/no. If yes, lateral window or trans-crestal approach; implant explantation-yes/no, if yes, date of explanation.

II. At $\mathrm{T} f$ : Probing depth at deepest site, bleeding on probing (BOP) - yes/no, plaque on supra-structure-yes/no.

III. Restoration (supra-structure): timing of restoration-late/immediate; restoration typeremovable, fixed single, fixed multiple; restoration quality-proper, overhanging margins, and ill-fitting margins (gap).

IV. Antagonist—absence of antagonist, teeth (intact or with filling material), tooth borne restoration (fixed/removable), and implant restoration (fixed/removable).

\subsection{Radiographic Data}

I. Mesial and distal bone level were measured at $\mathrm{T} 0$ and $\mathrm{T} f$. (Figures $1 \mathrm{a}$ and $1 \mathrm{~b}$, respectively). Radiographs were analyzed using a computer program (VixWin ProVrs. 1.5e Gendex Dental Systems. KAVO DENTAL 200 S Kraemer Blvd, Building E2 Brea, CA 92821, USA). Analogue radiographs were digitalized with a flatbed scanner (Epson Expression 1680pro; Seiko Epson Corp.) with 600 dpi resolution and eight-bit grey values. The image files were stored as TIFF files and analyzed using the computer program VixWin on a $24^{\prime}$ flat screen (Philips 243V5Q, $1920 \times 1080$; Philips) in a particular room under exclusion of natural or artificial light except the screen. After calibration using the implant's diameter, mesial and distal distances between implant shoulder and bone crest were measured using the ruler measurement tool. The degree of accuracy was $0.05 \mathrm{~mm}$. A single trained and calibrated investigator (MS) performed the evaluation of all radiographs. Replicate measurements were done on 23 implants.

II. Radiographic bone level change (the differences in radiographic bone level between $\mathrm{T} f$ and T0 were calculated separately for mesial and distal of each implant. The larger of them was chosen for further calculation of mean implant bone loss).

III. For the construction of a model of factors associated with peri-implant radiographic bone loss a new variable, "excess bone loss" was defined, consisting of peri-implant bone loss over the first year, of $1.5 \mathrm{~mm}$, and the subsequent loss per year of $0.1 \mathrm{~mm}$. The threshold for each implant was therefore calculated as $1.5 \mathrm{~mm}+0.1 *(\mathrm{~T} f-\mathrm{T} 0)$ years. Implants were categorized as 1 if the threshold was exceeded and 0 otherwise. With this variable, logistic regression was performed. 


\section{Statistical Analysis}

Data were tabulated in a computerized database (Microsoft Office Excel Version 16.0, Microsoft Corporation, Redmond, WA, USA). Statistical analysis was performed using Statistics Products Solutions Services (SPSS) 25.0 software for Windows (IBM North America, New York, NY, USA). Statistical data are presented as mean \pm standard deviation (mean $\pm \mathrm{SD}$ ).

Two-tailed $p$-values of 0.05 or less were considered statistically significant. Data from T0 and $\mathrm{T} f$ and changes that occurred during follow-up were analyzed.

- Bivariate analyses of factors influencing implant bone loss were performed using logistic regression for the calculation of the odds ratio (OR) with $95 \%$ confidence intervals (CI) and $p$-values.

- Mixed logistic regression analysis was performed to construct a model for assessment of the relation between general data, dental, and implant data. All variables with a $p$-value $<0.2$ in bivariate analyses were selected as candidates for the multivariate analysis [20].

- "Goodness-of-fit" of the model was elaborated with receiver operating characteristic (ROC) analyses. ROC analysis provides tools to select possibly optimal models and to discard suboptimal ones independently from (and prior to specifying) the cost context or the class distribution. ROC analysis is related in a direct and natural way to cost/benefit analysis of diagnostic decision making. ROC is a probability curve and the Area Under the Curve (AUC) represents degree or measure of separability. It tells how much a model is capable of distinguishing between classes. In the present study, the higher the AUC, the better the model explains the association between parameters and peri-implant bone loss. Values over 70\% indicate a good fit of the model [21].

\section{Results}

\subsection{General Data}

A total of 219 patients fulfilled the initial clinical $\geq 8$-years follow-up criterion. Of those, 37 patients were identified as also having orthoradial radiographs of the implants of adequate diagnostic quality. This cohort of patients received 142 implants. Four implants were lost during the follow-up period. Before implant installation, 35 patients (95\%) were diagnosed as periodontitis patients [22] (formerly, chronic periodontitis) [23] and the rest were gingivitis patients. The mean follow-up period was $11.7 \pm 3.7$ years (range $8-23$, median 10.5 years). Male/female ratio was $41 \% / 59 \%$ (15/22). Mean age at implant placement was $55 \pm 7.6$ years (range 34.7-74.), and no patients reported taking calcium channel blockers, phenytoin, or cyclosporin. Six patients (16\%) took anticoagulant medications. Thirteen patients $(53 \%)$ reported having cardiovascular diseases. Diabetes and osteoporosis were reported by $4(11 \%)$ and 2 patients $(5 \%)$, respectively. Eight patients (22\%) were smokers (Table 1$)$.

Table 1. General data.

\begin{tabular}{cc}
\hline Characteristics & $\%(n)$ \\
\hline Age (years) & $55 \pm 7.6(34.7-74)$ \\
\hline Gender (male/female) & $16 \%(6) 41 \%(15) / 59 \%(22)$ \\
\hline Smoking (no/yes) & $78 \%(29) / 22 \%(8)$ \\
\hline Systemic & $11 \%(4) / 53 \%(13) / 5 \%(2)$ \\
\hline Diabetes/CVD/Osteoporosis & 0 \\
\hline CaCB/Phenytoin/Cyclosporin & $16 \%(6)$ \\
\hline Anticoagulants
\end{tabular}

\subsection{Dental Data}

The mean number of teeth at T0 was $21.8 \pm 4.2$ (range 10-29), and the number of pre-existing implants was $1 \pm 1.5$ (range $0-5$ ). Number of sites with $P D \geq 5 \mathrm{~mm}$ was $6.7 \pm 8.5$ (range $0-40$ ). FMBS and 
PII at T0 were $19.5 \% \pm 15.4 \%(1 \%-80 \%)$ and $1.1 \pm 0.4(0.3-2)$, respectively. Supportive periodontal therapy (SPT) rate for each implant was calculated by dividing the number of SPT appointments by follow-up time (the time between T0 and Tf). SPT rate was $2.6 \pm 1.4(0-5) \mathrm{SPT} /$ year. The majority of implants (87) were maintained more than twice per year on average (Table 2).

Table 2. Dental data.

\begin{tabular}{ccc}
\hline Characteristics & $\boldsymbol{T}_{\boldsymbol{0}}$ & $\boldsymbol{T}_{\boldsymbol{f}}$ \\
\hline Mean patient $n$ teeth (range) & $21.8 \pm 4.2(10-29)$ & \\
Mean patient $n$ implants (range) & $1 \pm 1.5(0-5)$ & \\
Mean $n$ PD $\geq 5$ mm (range) & $6.7 \pm 8.5(0-40)$ & $6.9 \pm 9.2(0-44)$ \\
FMBS (\%) (range) & $19.5 \% \pm 15.4 \%(1-80 \%)$ & $24.5 \% \pm 16.3 \%(0-67 \%)$ \\
PI (range) & $1.1 \pm 0.4(0.3-2)$ & $1.3 \pm 0.5(0-2.5)$ \\
SPT/year & & $2.6 \pm 1.4(0-5)$ \\
\hline
\end{tabular}

\subsection{Implant Data}

A total of 142 implants were followed up to 23 years. Six implant brands were installed, which can be categorized in two main groups: the external hex group, consisting of 5 Brånemark ${ }^{\circledR}$ [Brånemark system ${ }^{\circledR}$ MKIII RP implant, Nobel Biocare AB, Göteborg, Sweden, (external hex, machined)], $83 \mathrm{I}^{\circledR}$ [Biomet 3i, Inc, Palm Beach Gardens, Florida, USA, (external hex, hybrid- machined top, dual acid etched bottom)], 5 Implant Direct ${ }^{\circledR}$ [Implant Direct, Valencia, CA, USA, (external hex, soluble blast medium blasted)], 11 MIS ${ }^{\circledR}$ [MIS Implant Technologies Ltd, Bar-Lev Industrial Zone, Israel, (external hex, sand-blasted, acid-etched)], 43 Steri Oss ${ }^{\circledR}$ [SteriOss Yorba Linda, CA, USA, (external hex, etched)], and the internal hex group, consisting of 70 Zimmer ${ }^{\circledR}$ [Zimmer Biomet Dental, Palm Beach Gardens, Florida, USA, (Internal hex, HA blasted)]. Implant length ranged between $10 \mathrm{~mm}$ and $16 \mathrm{~mm}$, and their diameters ranged between $3.7 \mathrm{~mm}$ and $5 \mathrm{~mm}$. Seventy-five implants $(52.8 \%)$ had an internal hex connection, whereas $67(47.2 \%)$ had an external hex. One hundred thirty-six implants (96\%) were placed in healed ridges (late implantation). Early and immediate implantation corresponded to $4(2.67 \%)$ and $2(1.33 \%)$ implants, respectively. Fifty-four implants (38\%) received additional GBR, of which $12(8.5 \%)$ had trans-crestal sinus augmentation and $32(22.5 \%)$ had lateral window sinus augmentation. Ninety-nine (70\%) were $10-12 \mathrm{~mm}$ long, and eighty-eight (62\%) implants were $3.7-4 \mathrm{~mm}$ in diameter. A total of $53(37 \%)$ implants were both $10-12 \mathrm{~mm}$ long and $3.7-4 \mathrm{~mm}$ in diameter.

All implant restorations were delayed loaded, predominantly fixed-multiple restorations (108 $(76 \%))$, with properly fitting margins (112 (78.9\%)). Six (14.3\%) presented overhanging margins, and $24(16.9 \%)$ were ill-fitted showing radiographic gaps between the crown and the supra-structure.

In all cases, antagonists were existing. Fifty-four (38\%) of the antagonists were intact teeth or teeth with plastic restorations (amalgam/composite), 23 (16.2\%) were implants, and $58(40.8 \%)$ were fixed restorations on either teeth or implants. Seven (5\%) removable antagonists were recorded. (Table 3).

\subsection{Radiographic Data}

Radiographic bone loss is temporally associated; therefore, we chose to use the criterion of "excess bone loss" defined as $1.5 \mathrm{~mm}$ for the first year followed by $0.1 \mathrm{~mm}$ for each additional year for the construction of the model. One hundred and nine (76.8\%) implants did not exhibit excess bone loss. Among patient related characteristics (e.g., age, gender, systemic health condition, and smoking) only osteoporosis was associated with excess bone loss $(p=0.028$, OR $=4.69, \mathrm{CI} 1.18-18.62)$. Moreover, clinical findings, including the number of teeth, number of sites with $\mathrm{PD} \geq 5 \mathrm{~mm}$, and plaque and bleeding scores, did not show any correlation with radiographic peri-implant bone loss. When it comes to implant-related data, only hex type, favoring external hex, was found to be borderline significantly correlated to radiographic peri-implant bone loss ( $p=0.059, \mathrm{OR}=2.19, \mathrm{CI} 0.97-4.96)$. Implant dimensions (diameter and length), GBR and sinus augmentation procedures were not associated with bone loss. Implant brands, type or quality of implant restoration, and type of 
antagonist restoration were also not found to be significantly associated with radiographic peri-implant bone loss. Intra-examiner reproducibility of radiographic bone measurements showed concordance correlation coefficient [24] of 0.99 or almost perfect [25].

Table 3. Implants related data.

\begin{tabular}{|c|c|}
\hline Characteristics & $\%(n)$ \\
\hline Deepest PD at implant $(\leq 3 / 4-6 / \geq 7 \mathrm{~mm})$ & $49.3 \%(70) / 42.3 \%(60) / 8.4 \%(2)$ \\
\hline BOP at implant (no/yes) & $16.7 \%(22) / 83.3 \%(110)$ \\
\hline PII at implant (no/yes) & $12 \%(7) / 88 \%(125)$ \\
\hline Timing of implantation (immediate/early/late) & $95.8 \%(136) / 2.8 \%(4) / 1.4 \%(2)$ \\
\hline $\begin{array}{l}\text { Implant dimensions: } \\
\text { Diameter }(3.7-4 \mathrm{~mm} / 4.1-5 \mathrm{~mm}) \\
\text { Length }(10-12 \mathrm{~mm} / 13-16 \mathrm{~mm})\end{array}$ & $\begin{array}{c}62 \%(88) / 38 \%(54) \\
69.7 \%(99) / 30.3 \%(43)\end{array}$ \\
\hline GBR (no/yes) & $62 \%(88) / 38 \%(54)$ \\
\hline Sinus augmentation (no/transcrestal/lateral window) & $69 \%(98) / 8.5 \%(12) / 22.5 \%(32)$ \\
\hline Restoration type (fixed single/multiple) & $24 \%(34) / 76 \%(108)$ \\
\hline $\begin{array}{l}\text { Restoration quality-proper/overhanging } \\
\text { margin/ill-fitting margin (gap) }\end{array}$ & $78.9 \%(112) / 4.2 \%(6) / 16.9 \%(24)$ \\
\hline Antagonist (tooth/implant/fixed/removable) & $38 \%(54) / 16.2 \%(23) / 40.8 \%(58) / 5 \%$ (7) \\
\hline
\end{tabular}

\subsection{Intervariable Interactions}

Intervariable interactions were calculated prior to multivariate analysis. Bone loss was significantly lower among external hex implants, installed without GBR $(p=0.008$, OR $=8$, CI 1.71-37.42). Interestingly, no significant association between the connection type groups was found when implant installation was combined with GBR $(p=0.811)$. The significant difference between connection types existed only in the lower jaw ( $p=0.048, \mathrm{OR}=3.49, \mathrm{CI} 1.01-12.07)$. The number of teeth and the number of implants at $\mathrm{T} 0$ were significantly correlated with bone loss. When less than 20 teeth and 2 or more implants were present at T0, the odds-ratio for implant bone loss was 3.6 (CI 1.03-12.56), $(p=0.045)$. Implants having a length of $10-12 \mathrm{~mm}$ as well as a diameter of $3.7-4 \mathrm{~mm}$ were significantly more successful ( $p=0.033, \mathrm{OR}=2.71, \mathrm{CI} 1.08-6.79)$. (Table 4)

Table 4. Intervariable interactions.

\begin{tabular}{|c|c|c|c|c|}
\hline Characteristics & $\%(n) *$ Excess Bone Loss & $p$ Value & ** OR & $* * * \mathrm{CI}$ \\
\hline $\begin{array}{l}\text { With GBR } \\
\text { ext. hex } \\
\text { int. hex }\end{array}$ & $\begin{array}{c}29 \%(9) \\
26.1 \%(6)\end{array}$ & 0.811 & & \\
\hline $\begin{array}{l}\text { Without GBR } \\
\text { ext. hex } \\
\text { int. hex }\end{array}$ & $\begin{array}{c}5.4 \%(2) \\
31.4 \%(16)\end{array}$ & 0.008 & 8 & $1.71-37.42$ \\
\hline $\begin{array}{c}\mathrm{T}_{0} n \text { Teeth and } n \text { Implants } \\
\geq 20 \text { and }<2 \\
<20 \text { or } \geq 2 \\
<20 \text { and } \geq 2\end{array}$ & $\begin{array}{c}11.8 \%(4) \\
23.9 \%(17) \\
32.4 \%(12)\end{array}$ & $\begin{array}{l}0.153 \\
0.045\end{array}$ & 3.6 & $1.03-12.56$ \\
\hline $\begin{array}{l}\text { Upper jaw } \\
\text { ext. hex } \\
\text { int. hex }\end{array}$ & $\begin{array}{c}20 \%(6) \\
27.1 \%(13)\end{array}$ & 0.48 & & \\
\hline $\begin{array}{l}\text { Lower jaw } \\
\text { ext. hex } \\
\text { int. hex }\end{array}$ & $\begin{array}{l}13.2 \%(5) \\
34.6 \%(9)\end{array}$ & 0.048 & 3.49 & $1.01-12.07$ \\
\hline $\begin{array}{l}\text { Implant dimensions } \\
\text { Length Diameter } \\
\leq 12 \text { and } \leq 4 \\
>13 \text { or }>4\end{array}$ & $\begin{array}{c}13.2 \%(7) \\
29.2 \%(26)\end{array}$ & 0.033 & 2.71 & $1.08-6.79$ \\
\hline
\end{tabular}

* excess bone loss-implants in which radiographic bone loss exceeded $1.5 \mathrm{~mm}$ in the first year and $0.1 \mathrm{~mm}$ every additional year during the follow-up. ${ }^{* *}$ OR-Odds Ratio. ${ }^{* * *} \mathrm{CI}-$ Confidence Interval. 


\subsection{Mixed Logistic Regression}

A combination of the following parameters was explanatory for implant bone stability: osteoporosis $(p<0.007, \mathrm{OR}=9.89$, CI 1.85-52.8), smoking $(p<0.048$, OR $=2.71, \mathrm{CI} 1.01-7.27)$, external hex connection without GBR procedure $(p<0.008, \mathrm{OR}=11.98, \mathrm{CI} 1.93-74.43)$, and implant diameter of $4 \mathrm{~mm}$ or less and length of $12 \mathrm{~mm}$ or less ( $p=0.021, \mathrm{OR}=4.53, \mathrm{CI} 1.25-16.38)$.

\subsection{ROC Curve}

The ROC curve (Figure 2) presents $X$ and $Y$ axes depicting, respectively, relative trade-offs between true positive (sensitivity) and false positive (1-specificity). The "goodness-of-fit" of the model was checked on each one of the implants. It was expressed as the Area Under the Curve (AUC). The AUC in the present model amounted to $76.9 \%$ (Standard Error $4.6 \%$, CI 67.8\%-86\%).

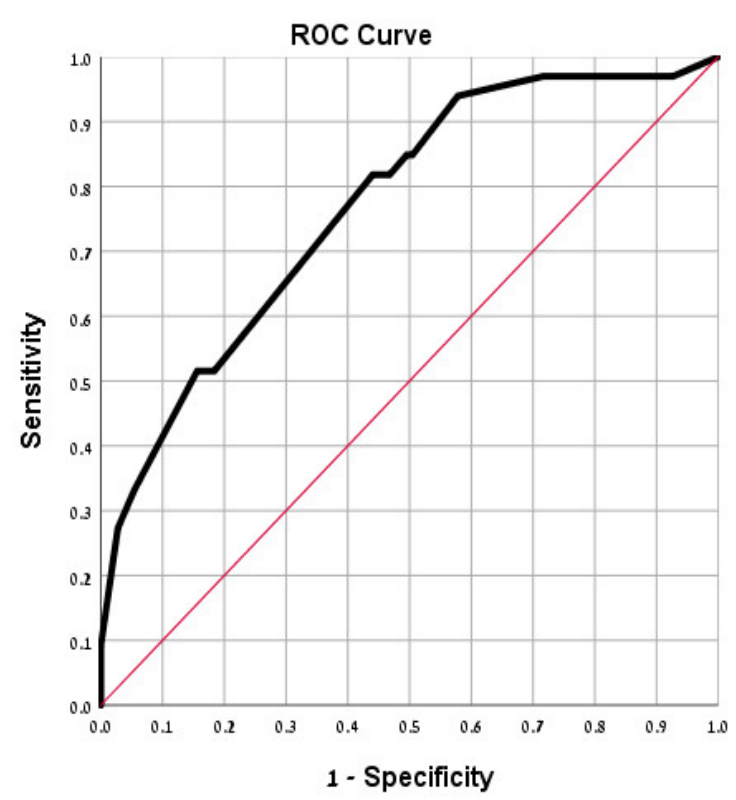

Figure 2. Receiver operating curve (ROC) analysis for 'goodness-of-fit' of the found model for implant success. The area under the ROC curve (AUC) is significant $(p<0.0001)$.

\section{Discussion}

In the present study, external hex implants placed without bone augmentation presented with less long-term bone loss. The addition of bone augmentation procedures masked the effect of the connection type. Additionally, implants of $10-12 \mathrm{~mm}$ in length and of 3.7-4 mm in diameter presented less bone loss. The good AUC of the ROC model indicates its good fit. These findings partly support Jafarian et al [26], who reported that the brand, length, and diameter of implants affected the survival time, failure rate, and time to failure. In the Jafarian et al. study, implants with $10 \mathrm{~mm}$ length and 5.5-6 $\mathrm{mm}$ diameter had the highest failure rate; the lowest failure rate occurred in implants of $11.5 \mathrm{~mm}$ in length and 3-3.5 $\mathrm{mm}$ in diameter. In clinical practice, the choice of implant size is associated with the available bone volume and is at the discretion of the surgeon. Still, it seems that larger is not necessarily better when it comes to implant survival and success. Whereas large diameter seems to be a plausible factor contributing to the risk of peri-implant bone loss (the larger the diameter, the less thick the bone surrounding the implant), implant length does not seem an obvious risk. A possible explanation why long implants have a higher risk for bone loss is that bone heating from the drilling procedure is directly associated with the drilling depth (and implant length) [27].

Currently, there are variations in the criteria for acceptable bone loss during the various life stages of the implant. On the one hand, some report an acceptable bone loss of $<0.5 \mathrm{~mm}$ as a common standard [28]; on the other hand, more recent publications define periimplantitis as bone level $\geq 3 \mathrm{~mm}$ 
apical of the most coronal portion of the intra-osseous part of the implant [9]. The most reported criterion is that by Albrektsson et al., in which the mean bone loss over the first-year post implant installation up to $1.5 \mathrm{~mm}$, and the subsequent loss per year around $0.1 \mathrm{~mm}$, may be defined as acceptable [8]. Based on that, and taking into account an inherent mean error of $0.5 \mathrm{~mm}$ in bone level measurements [9] a minimum of six years, radiographic follow-up should be performed in order to detect bone loss in excess of $0.5 \mathrm{~mm}$ after the first year. We chose the 8-year lower inclusion threshold (and not 10 years or longer) in order to have a sample size large enough and with sufficient follow-up to obtain detectable bone loss.

Regarding connection type, our results were in line with much of the literature. Bone levels around external hex connection were stable and similar to [29,30] or smaller [31] than those observed at internal hex connection implants. Still, some publications favor internal hex connection implants regarding bone resorption [32-34]. It should be acknowledged that the connection type groups were composed of different brands with different implant surface-treatments, and possibly other differences as well; however, no significant statistical association was found between brand and bone loss. Similar conclusions were found by Lee et al. (2016) and Díaz-Sánchez et al. (2019) [35,36].

Osteoporosis is associated with an increase in peri-implant bone loss [37]. In our study, significantly more radiographic bone loss was observed in the two patients with osteoporosis that received nine implants. Although osteoporosis is not associated with increased implant loss, the present finding points to the need for further long-term investigation of implants in patients with osteoporosis.

Smoking has long been considered a risk factor for periodontal and peri-implant diseases, and in the present study smoking was found to be significantly correlated with peri-implant radiographic bone loss. Similar findings were reported in by Rinke et al. (2011) [11] and by Schwarz et al. (2017) [38], who reported odds ratio for periimplantitis among smokers of 2.7, similar to the present study.

Progression of peri-implantitis may have similarities with periodontitis; however, in the present study no association was found between factors traditionally associated with periodontitis such as FMBS, number of PD $\geq 5 \mathrm{~mm}$, SPT rate, restoration related variables, and the observed peri-implant bone loss. This finding may be due to the fact that at least some patients may have had recurrent periodontal disease during the follow-up period. Contrary to the present study, in a systematic review by Lin et al. [39], it was shown that residual periodontal pockets and high levels of BOP and PI had a negative effect on peri-implant bone levels in patients with history of periodontitis and under regular SPT. The lack of association in the present study may be explained by SPT frequency, since $64.4 \%$ of the implants (87 implants) received SPT more than twice per year. The frequent maintenance utilized in the private practice masked the effect of poor oral hygiene on bone levels. In this study, all implants were rehabilitated with either single or multiple fixed restorations, none of which were associated with any difference in peri-implant bone loss. There were no overdenture patients to compare with; however, higher rates of marginal bone loss were reported among implants rehabilitated with overdentures vs. fixed restorations [40].

Weaknesses and strengths: The main drawbacks of the study are its retrospective design, the small sample size, and the heterogeneity in implant brands. Long-term retrospective studies often exhibit similar issues (with 75-101 implants in 26-63 patients and with up to seven implant brands) [13,41,42]. Additionally, restorations were performed by referring dentists, the uniformity of which was not controlled. Interestingly, the type of restoration or its apparent quality were not found to be associated with peri implant radiographic bone loss. Heterogeneity of implant systems can be considered a drawback but also an advantage, contributing to generalizability of the results regarding the lack of major differences in outcome between different implant systems of similar design [35,36].

\section{Conclusions}

Within the limitations of the study, the following conclusions can be made. Implants with an external hex placed without GBR and implants having a length of $10-12 \mathrm{~mm}$ as well as diameter of 
3.7-4 mm showed less peri-implant radiographic bone loss in this long-term follow-up. Patients with osteoporosis and smokers were prone to increased radiographic peri-implant bone-loss.

Author Contributions: Conceptualization, M.S. and J.H.; Data curation, A.B.D.; Formal analysis, A.B.D.; Investigation, J.H.; Methodology, M.S. and J.H.; Writing-review and editing, M.S. and J.H. All authors have read and agreed to the published version of the manuscript.

Funding: This research received no external funding.

Acknowledgments: We thank Tanya Mashiach (Statistician, Rambam Health Care Campus, P.O.B 9602, Haifa 3109601, Israel) for performing the statistical analysis for this article.

Conflicts of Interest: The authors declare no conflict of interest.

\section{References}

1. Buser, D.; Mericske-Stern, R.; Bernard, J.P.P.; Behneke, A.; Behneke, N.; Hirt, H.P.; Belser, U.C.; Lang, N.P. Long-term evaluation of non-submerged ITI implants. Part 1: 8-year life table analysis of a prospective multi-center study with 2359 implants. Clin. Oral Implant. Res. 1997, 8, 161-172. [CrossRef]

2. E Pjetursson, B.; Asgeirsson, A.G.; Zwahlen, M.; Sailer, I. Improvements in Implant Dentistry over the Last Decade: Comparison of Survival and Complication Rates in Older and Newer Publications. Int. J. Oral Maxillofac. Implant. 2014, 29, 308-324. [CrossRef]

3. De Angelis, F.; Papi, P.; Mencio, F.; Rosella, D.; Di Carlo, S.; Pompa, G. Implant survival and success rates in patients with risk factors: Results from a long-term retrospective study with a 10 to 18 years follow-up. Eur. Rev. Med. Pharmacol. Sci. 2017, 21, 433-437.

4. Van Velzen, F.J.; Ofec, R.; Schulten, E.A.J.M.; Bruggenkate, C.M.T. 10-year survival rate and the incidence of peri-implant disease of 374 titanium dental implants with a SLA surface: A prospective cohort study in 177 fully and partially edentulous patients. Clin. Oral Implant. Res. 2015, 26, 1121-1128. [CrossRef]

5. Araujo, M.G.; Lindhe, J. Peri-implant health. J. Clin. Periodontol. 2018, 45, S230-S236. [CrossRef]

6. Lindquist, L.W.; Carlsson, G.E.; Jemt, T. A prospective 15-year follow- up study of mandibular fixed prostheses supported by osseointegrated implants. Clinical results and marginal bone loss. Clin. Oral Implant. Res. 1996, 7, 329-336. [CrossRef]

7. Cochran, D.L.; Nummikoski, P.V.; Schoolfield, J.D.; Jones, A.A.; Oates, T.W. A Prospective Multicenter 5-Year Radiographic Evaluation of Crestal Bone Levels Over Time in 596 Dental Implants Placed in 192 Patients. J. Periodontol. 2009, 80, 725-733. [CrossRef]

8. Albrektsson, T.; Zarb, G.; Worthington, P.; Eriksson, A.R. The long-term efficacy of currently used dental implants: A review and proposed criteria of success. Int. J. Oral Maxillofac. Implant. 1986, 1, 11-25.

9. Berglundh, T.; Armitage, G.; Araujo, M.G.; Avila-Ortiz, G.; Blanco, J.; Camargo, P.M.; Chen, S.; Cochran, D.; Derks, J.; Figuero, E.; et al. Peri-implant diseases and conditions: Consensus report of workgroup 4 of the 2017 World Workshop on the Classification of Periodontal and Peri-Implant Diseases and Conditions. J. Clin. Periodontol. 2018, 45, S286-S291. [CrossRef]

10. Roccuzzo, M.; De Angelis, N.; Bonino, L.; Aglietta, M. Ten-year results of a three-arm prospective cohort study on implants in periodontally compromised patients. Part 1: Implant loss and radiographic bone loss. Clin. Oral Implant. Res. 2010, 21, 490-496. [CrossRef]

11. Rinke, S.; Ohl, S.; Ziebolz, D.; Lange, K.; Eickholz, P. Prevalence of periimplant disease in partially edentulous patients: A practice-based cross-sectional study. Clin. Oral Implant. Res. 2011, 22, 826-833. [CrossRef]

12. Mir-Mari, J.; Mir-Orfila, P.; Figueiredo, R.; Valmaseda-Castellón, E.; Gay-Escoda, C. Prevalence of peri-implant diseases. A cross-sectional study based on a private practice environment. J. Clin. Periodontol. 2012, 39, 490-494. [CrossRef]

13. Frisch, E.; Wild, V.; Ratka-Krüger, P.; Vach, K.; Sennhenn-Kirchner, S. Long-term results of implants and implant-supported prostheses under systematic supportive implant therapy: A retrospective 25-year study. Clin. Implant. Dent Relat. Res. 2020. [CrossRef] [PubMed]

14. Alsaadi, G.; Quirynen, M.; Michiles, K.; Teughels, W.; Komárek, A.; Van Steenberghe, D. Impact of local and systemic factors on the incidence of failures up to abutment connection with modified surface oral implants. J. Clin. Periodontol. 2008, 35, 51-57. [CrossRef] 
15. Pihlstrom, B.L.; Carlson, J.F.; Smith, Q.T.; Bastien, S.A.; Keenan, K.M. Prevention of Phenytoin Associated Gingival Enlargement-A 15-Month Longitudinal Study. J. Periodontol. 1980, 51, 311-317. [CrossRef]

16. Lucas, R.M.; Howell, L.P.; Wall, B.A. Nifedipine-Induced Gingival Hyperplasia: A Histochemical and Ultrastructural Study. J. Periodontol. 1985, 56, 211-215. [CrossRef]

17. Seymour, R.A.; Jacobs, D.J. Cyclosporin and the gingival tissues. J. Clin. Periodontol. 1992, 19, 1-11. [CrossRef]

18. Ainamo, J.; Bay, I. Problems and proposals for recording gingivitis and plaque. Int. Dent. J. 1975, 25, $229-235$.

19. Silness, J.; Löe, H. Periodontal disease in pregnancy. II Corelation between oral hygiene and periodontal condition. Acta Odontol. Scand. 1964, 22, 112-135. [CrossRef]

20. Katz, M.H. Multivariable Analysis: A Practical Guide for Clinicians and Public Health Researchers, 3rd ed.; Cambridge University Press: Cambridge, UK, 2011.

21. Hosmer, D.W.; Lemeshow, S. Applied Logistic Regression, 2nd ed.; John Wiley \& Sons, Inc.: Hoboken, NJ, USA, 2000; pp. 156-164.

22. Trombelli, L.; Farina, R.; Silva, C.O.; Tatakis, D.N. Plaque-induced gingivitis: Case definition and diagnostic considerations. J. Periodontol. 2018, 89, S46-S73. [CrossRef]

23. Armitage, G.C. Development of a Classification System for Periodontal Diseases and Conditions. Ann. Periodontol. 1999, 4, 1-6. [CrossRef]

24. Lin, L.I. A concordance correlation coefficient to evaluate reproducibility. Biometrics 1989, 45, $255-268$. [CrossRef]

25. McBride, G.B. A Proposal for Strength-of-Agreement Criteria for Lin'S Concordance Correlation Coefficient. NIWA Client Report: HAM2005-062; National Institute of Water \& Atmospheric Research: Hamilton, New Zealand, 2005.

26. Jafarian, M.; Bayat, M.; Pakravan, A.-H.; Emadi, N. Analysis of the Factors Affecting Surgical Success of Implants Placed in Iranian Warfare Victims. Med. Princ. Pract. 2016, 25, 449-454. [CrossRef]

27. Gehrke, S.A.; Aramburú Júnior, J.S.; Pérez-Albacete Martínez, C.; Ramirez Fernandez, M.P.; Maté Sánchez de Val, J.E.; Calvo-Guirado, J.L. The influence of drill length and irrigation system on heat production during osteotomy preparation for dental implants: An ex vivo study. Clin. Oral Implant. Res. 2018, 29, 772-778. [CrossRef]

28. Albrektsson, T.; Buser, D.; Sennerby, L. On crestal/marginal bone loss around dental implants. Int. J. Periodontics Restor. Dent. 2013, 33, 9-11.

29. Argollo, L.M.D.S.C.D.T.E.; Francischone, C.E.; Duarte, L.R.; Senna, P.M.; Assis, N.M.S.P.; Sotto-Maior, B.S. Marginal Bone Remodeling Around Dental Implants with Hexagon External Connection After 10 Years: A Case Series with 10 to 19 Years of Function. Int. J. Periodontics Restor. Dent. 2019, 39, 703-708.

30. Glibert, M.; Vervaeke, S.; Jacquet, W.; Vermeersch, K.; Östman, P.-O.; De Bruyn, H. A randomized controlled clinical trial to assess crestal bone remodeling of four different implant designs. Clin. Implant. Dent. Relat. Res. 2018, 20, 455-462. [CrossRef]

31. Pjetursson, B.E.; A Valente, N.; Strasding, M.; Zwahlen, M.; Liu, S.; Sailer, I. A systematic review of the survival and complication rates of zirconia-ceramic and metal-ceramic single crowns. Clin. Oral Implant. Res. 2018, 29, 199-214. [CrossRef]

32. Bidra, A.S.; Rungruanganunt, P. Clinical Outcomes of Implant Abutments in the Anterior Region: A Systematic Review. J. Esthet. Restor. Dent. 2013, 25, 159-176. [CrossRef]

33. Galindo-Moreno, P.; Fernández-Jiménez, A.; Avila-Ortiz, G.; Silvestre, F.; Hernández-Cortés, P.; Wang, H. Marginal bone loss around implants placed in maxillary native bone or grafted sinuses: A retrospective cohort study. Clin. Oral Implant. Res. 2014, 25, 378-384. [CrossRef]

34. Galindo-Moreno, P.; León-Cano, A.; Ortega-Oller, I.; Monje, A.; O'valle, F.; Catena, A. Marginal bone loss as success criterion in implant dentistry: Beyond $2 \mathrm{~mm}$. Clin. Oral Implant. Res. 2015, 26, e28-e34. [CrossRef]

35. Lee, S.-Y.; Koak, J.-Y.; Kim, S.-K.; Rhyu, I.-C.; Ku, Y.; Heo, S.-J.; Han, C.-H. A Long-Term Prospective Evaluation of Marginal Bone Level Change Around Different Implant Systems. Int. J. Oral Maxillofac. Implant. 2016, 31, 657-664. [CrossRef] [PubMed]

36. Díaz-Sánchez, R.-M.; Delgado-Muñoz, J.-M.; Serrera-Figallo, M.-Á.; González-Martín, M.-I.; Torres-Lagares, D.; Gutiérrez-Pérez, J.-L. Analysis of marginal bone loss and implant stability quotient by resonance frequency analysis in different osteointegrated implant systems. Randomized prospective clinical trial. Med. Oral Patol. Oral Cir. Bucal 2019, 24, e260-e264. [CrossRef] [PubMed] 
37. De Medeiros, F.; Kudo, G.; Leme, B.; Saraiva, P.; Verri, F.; Honório, H.; Pellizzer, E.; Júnior, J.F.S. Dental implants in patients with osteoporosis: A systematic review with meta-analysis. Int. J. Oral Maxillofac. Surg. 2018, 47, 480-491. [CrossRef] [PubMed]

38. Schwarz, F.; Becker, K.; Sahm, N.; Horstkemper, T.; Rousi, K.; Becker, J. The prevalence of peri-implant diseases for two-piece implants with an internal tube-in-tube connection: A cross-sectional analysis of 512 implants. Clin. Oral Implant. Res. 2017, 28, 24-28. [CrossRef]

39. Lin, C.-Y.; Chen, Z.; Pan, W.-L.; Wang, H.-L. Is History of Periodontal Disease Still a Negative Risk Indicator for Peri-implant Health under Supportive Post-implant Treatment Coverage? A Systematic Review and Meta-analysis. Int. J. Oral Maxillofac. Implant. 2020, 35, 52-62. [CrossRef]

40. Rammelsberg, P.; Kappel, S.; Bermejo, J.L. Effect of prosthetic restoration on implant survival and success. Clin. Oral Implant. Res. 2017, 28, 1296-1302. [CrossRef]

41. Woelber, J.P.; Ratka-Krueger, P.; Frisch, E.; Vach, K. Decementation Rates and the Peri-Implant Tissue Status of Implant-Supported Fixed Restorations Retained via Zinc Oxide Cement: A Retrospective 10-23-Year Study. Clin. Implant. Dent. Relat. Res. 2016, 18, 917-925. [CrossRef]

42. Frisch, E.; Vach, K.; Ratka-Krueger, P. Impact of supportive implant therapy on peri-implant diseases: A retrospective 7-year study. J. Clin. Periodontol. 2020, 47, 101-109. [CrossRef]

Publisher's Note: MDPI stays neutral with regard to jurisdictional claims in published maps and institutional affiliations.

(C) 2020 by the authors. Licensee MDPI, Basel, Switzerland. This article is an open access article distributed under the terms and conditions of the Creative Commons Attribution (CC BY) license (http://creativecommons.org/licenses/by/4.0/). 